\title{
RET mutated C-cells proliferate more rapidly than non-mutated neoplastic cells
}

\author{
Cristina Romei ${ }^{1}$, Teresa Ramone ${ }^{1}$, Chiara Mulè̀ , Alessandro Prete ${ }^{1}$, Virginia Cappagli ${ }^{1}$, Loredana Lorusso ${ }^{1}$, \\ Liborio Torregrossa ${ }^{2}$, Fulvio Basolo ${ }^{2}$, Raffaele Ciampi ${ }^{1}$ and Rossella Elisei ${ }^{1}$
}

${ }^{1}$ Endocrine Unit, Department of Clinical and Experimental Medicine, University of Pisa, Pisa, Italy

2Department of Surgical, Medical, Molecular Pathology, University of Pisa, Pisa, Italy

Correspondence should be addressed to R Elisei: rosella.elisei@med.unipi.it

\begin{abstract}
A statistically significant higher prevalence of the RET p.Met918Thr somatic mutation, identified by direct sequencing, was previously reported in MTC $>2 \mathrm{~cm}$ than in smaller tumors. Aim of this study was to correlate the full RET and RAS mutation profile, identified by a Next Generation Sequencing approach, with the growth rate, proliferation and tumor size of MTC. Data of 149 sporadic MTC patients were correlated with RET mutations and Ki67 positivity. Eighty-one cases had a somatic RET mutation, 40 had a RAS mutation and 28 were negative. A statistically significant higher prevalence of $R E T$ mutations was found in MTC $>2 \mathrm{~cm}$. A higher prevalence of RET more aggressive mutations, higher allelic frequencies and, higher percentage of Ki67 positive cells were found in larger tumors which had also a worse outcome. Our study highlights the predominant role of RET somatic mutations in MTC tumorigenesis. We demonstrate that RET mutation prevalence and allelic frequency (AF) are significantly higher in larger tumors. Based on these results, we can conclude that RET mutated C-cells's growth and proliferation are more rapid than those of non-mutated cells and give origin to bigger and more aggressive MTC.
\end{abstract}

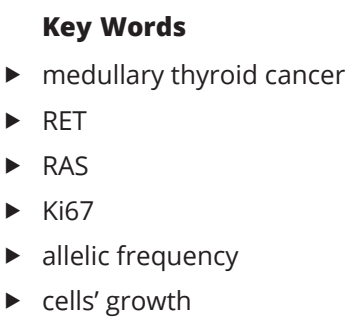

Endocrine Connections (2021) 10, 124-130

\section{Introduction}

Medullary Thyroid Carcinoma (MTC) accounts for about $5-7 \%$ of all thyroid cancer and can occur in a hereditary $(25 \%)$ or a sporadic form (75\%) (1).

According to the Next Generation Studies published in the last years $(2,3,4,5,6)$, somatic RET mutations are the most frequent alterations found in sporadic MTC. Although a large spectrum of RET mutations are described, the commonest alteration is the p.Met918Thr mutation in exon 16 of the RET gene (1). In addition to somatic RET mutations, sporadic MTC shows the presence of somatic RAS mutations that have been mostly reported in RET negative tumours and are almost always mutually exclusive with RET mutations $(7,8)$. RET somatic mutations have been reported to be a factor of a bad prognosis and are significantly associated with a more aggressive biological behavior and a reduced survival $(9,10,11)$. Although less investigated, RAS mutations seem to predict a better outcome when compared to somatic RET mutations $(7,9)$.

We previously demonstrated that the presence of a somatic RET p.Met918Thr mutation correlated with larger tumor size while it was significantly lower in tumors smaller than $2 \mathrm{~cm}$ (12). We hypothesized that p.Met918Thr mutation might not be an early event or that it could be present from the beginning but only in a subpopulation of cells not detectable with the conventional sequencing analysis because of its low sensitivity. This latter hypothesis has been supported by the evidence of RET mutation heterogeneity in about $20 \%$ of MTC $(13,14)$. However, due to the low sensitivity of the Sanger method and to the fact that only RET exon 11 and 16 have been investigated, the problem of false

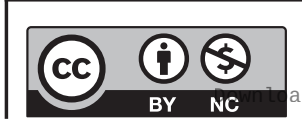

This work is licensed under a Creative Commons Attribution-NonCommercial 4.0 International License. ded from Bioscientifica.com at 04/26/2023 06:11:16AM 
negative cases should be considered as a bias in the former studies.

In the present study, we correlated the prevalence of any type of RET and RAS somatic mutations, as obtained with a Next Generation Sequencing (NGS) approach, with the MTC tumor size. Moreover, the correlation of their allelic frequency (AF) and the size of the tumor was evaluated to better understand their driver role in the tumoral transformation of the original C cells. Finally, the correlation with Ki67 positivity, that is an index of cell proliferation, with the size and the RET mutations was also analyzed.

\section{Patients and methods}

Our study group was represented by 149 MTC patients belonging to a larger series of 201 MTC patients submitted to total thyroidectomy and central neck dissection at our hospital whose tumoral tissues were analyzed by NGS for many gene alterations as previously reported (15). To the purpose of this study we included only the 149 cases analyzed on the primary tumor. All patients had no history of familial disease, were negative for the presence of other endocrine neoplasia and no germline RET mutations were found.

Clinical, biochemical and pathological data, with particular regard to tumor size, were collected from a computerized database. Cases were classified according to the size of the tumor as follows: group $1, \leq 1 \mathrm{~cm}$; group 2, >1 and $\leq 2 \mathrm{~cm}$; group $3,>2$ and $\leq 3 \mathrm{~cm}$; and group $4,>3 \mathrm{~cm}$.

Data about the presence or absence of RET and RAS somatic mutations were retrieved from the row data of the previous study (15), including the allelic frequency of the driver mutations.

Ki67 proliferative index was evaluated by immunohistochemistry. Five micrometer sections were cut from formalin-fixed paraffin-embedded (FFPE) blocks for 130 out of 149 cases. Ki67 immunostaining was performed automatically by the Ventana Benchmark immunostaining system (Ventana Medical Systems, Inc., Tucson, AZ) using a rabbit monoclonal primary antibody (immunoglobulin (Ig)G) directed against the C-terminal portion of Ki67 (CONFIRM anti-Ki67, clone 30-9; Ventana). Neoplastic cells were considered positive when the nuclei showed an immunoreactivity variable from weak to strong; neoplastic cells without nuclear immunoreactivity were considered as negative. Ki67 score was independently evaluated by two pathologists
(L T and F B) who were blinded to the clinicopathologic data. Immunostaining was evaluated using a standard Leica DM4000 microscope with the 'hot spots' method: the field under high power magnification (original magnification, $\times 40$ ) with the highest apparent Ki67 index was selected. The Ki67 score was defined as the percentage of positive cells among a minimum of 100 neoplastic cells. The results were scored according to the number of Ki67 positive cells: $<3 \%$ as low, $3-20 \%$ as intermediate and $>20 \%$ as high (16).

An informed consent form for RET genetic screening and other clinical procedures was signed by all patients. The present study was approved by the Institutional Review Board and by the 'Comitato Etico Regionale per la Sperimentazione Clinica della Regione Toscana' Prot $\mathrm{n}$ $6714,05 / 02 / 2019$.

\section{Statistics}

The statistical analysis was performed with the Chisquare test and with One-way ANOVA according to the studied variables and using the GraphPad Prism version 7.00 software.

\section{Results}

We distinguished 149 MTC cases according to the size of the primary tumor. As shown in Table 1 , in this subgroup of primary tissues, we found 81 (54\%) cases with a somatic RET mutation, 40 (27\%) cases with RAS mutations and 28 (19\%) cases that were negative. Among the RAS positive cases, 27 were positive for HRAS and 13 for KRAS respectively. Data on the presence of the somatic mutations were retrieved by a larger study performed in our center and already published (15).

As shown in Fig. 1 panel A, RET somatic mutations were the most prevalent in each group. However, a statistically significant different mutation profile

Table 1 Prevalence of RET and RAS mutations in the different size group.

\begin{tabular}{|c|c|c|c|c|}
\hline Group & $\begin{array}{c}\text { Number of } \\
\text { patients }\end{array}$ & $\begin{array}{c}\text { RET } \\
\text { positive, } \\
n(\%)\end{array}$ & $\begin{array}{c}\text { RAS } \\
\text { positive, } \\
n(\%)\end{array}$ & Negative \\
\hline $\mathrm{A}(\mathrm{X} \leq 1 \mathrm{~cm})$ & 36 & $13(36)$ & $11(30)$ & $12(34)$ \\
\hline $\mathrm{B}(1<\mathrm{X} \leq 2 \mathrm{~cm})$ & 55 & $28(51)$ & $17(31)$ & $10(18)$ \\
\hline$C(2<x \leq 3 \mathrm{~cm})$ & 29 & $20(69)$ & $8(27)$ & $1(4)$ \\
\hline $\mathrm{D}(3<\mathrm{X} \leq 4 \mathrm{~cm})$ & 29 & $20(69)$ & $4(14)$ & $5(17)$ \\
\hline Total & 149 & $81(55)$ & $40(27)$ & $28(18)$ \\
\hline
\end{tabular}


$(P=0.02)$ was observed in the four groups with the highest prevalence $(20 / 29,69 \%)$ of the RET mutations found in MTC cases with the largest size (group 3 and 4) and the lowest prevalence in group $2(28 / 51,11.8 \%)$ and 1 (13/36, 36\%). At variance, RAS positive cases and RET/RAS negative cases were found to be more frequent in smaller tumors ( 1 and 2 ). The mutation profile was also compared between tumors smaller and larger than $2 \mathrm{~cm}$. As shown in Fig. 1 panel B, the prevalence of RET positive cases was significantly higher in tumors larger than $2 \mathrm{~cm}$ while the prevalence of RAS positive and RET/RAS negative cases was lower in larger tumors.

We then focused on the different types of RET mutations according to the American thyroid association risk classification (17) as highest, high and moderate. As shown in Fig. 2 panel A, a gradual increase of the highest risk RET mutation (i.e. p.Met918Thr) has been observed with the increase of tumor size and a simultaneous gradual decrease was observed for high and moderate RET mutations $(P=0.0027)$. When considering the distribution of the different RET mutations in tumors either smaller (group 1 and 2) or larger (group 3 and 4) than $2 \mathrm{~cm}$, we observed that in the group $1+2$ RET mutations were uniformly distributed (highest 29.3\%, high 36.6\% and moderate $34 \%$ ) while in the group $3+4$, a significant greater prevalence of the highest RET mutations (29/40, $72.5 \%)$ was found with respect to the high $(7 / 40,17.5 \%)$ and the moderate $(4 / 40,10 \%)$ RET mutations.

As shown in Fig. 3 panels $\mathrm{A}$ and $\mathrm{B}$, the AF of RET mutations was significantly higher in larger tumors both when comparing the four different groups (group 1, mean AF $23.42 \pm 10.38$; group 2, mean AF $29.49 \pm 11.16$; group 3 , mean AF $39.27 \pm 9.3$, group 4 mean AF $42.48 \pm 11.16$ ) and when comparing group $1+2$ and group $3+4$ (group $1+2$, mean AF 27.51 \pm 10.38 ; group $3+4$ mean $\mathrm{AF}$ $40.91 \pm 12.63)$. In addition, the RET AF was higher in tumors of group $3+4$ than in group $1+2$ for every type of RET mutations (moderate: $46.72 \%$ vs $29.72 \%$, high: $39.48 \%$ vs $25.52 \%$, highest: $41.52 \%$ vs $27.7 \%$, respectively).
In particular, when we focused on the p.Met918Thr, we observed a statistically significant increase in the AF of this mutation with the increase of tumor size (group 1, mean AF $18.16 \pm 8.6$; group 2, mean AF $28.9 \pm 13.8$; group 3 , mean AF $39.8 \pm 13.1$, group 4 mean AF $44.3 \pm 16.3$ ).

As far as the AF of RAS mutations was concerned, although a trend of increase was observed, there was no a statically significant difference neither when comparing the four different groups (group 1, mean AF $29.8 \pm 11.9$; group 2, mean AF $33.87 \pm 12.2$; group 3, mean AF $36.13 \pm 11.4$, group 4 mean AF $46.62 \pm 4.6$ ) (Fig. 3 panel C) nor when comparing group $1+2$ and group $3+4$ (group $1+2$, mean $\mathrm{AF} 32.27 \pm 12.08$; group $3+4$ mean $\mathrm{AF}$ $39.63 \pm 107$ ) (Fig. 3 panel D).

Ki67 positive expression was high in 15/130 (11.5\%), intermediate in $79 / 129(60.8 \%)$, low in $34 / 129$ (26.2\%) and negative in $2 / 149$ (1.5\%). A statistically high significant correlation $(P<0.0001)$ was found when the Ki67 low, intermediate and high positivity was analyzed according to the tumor size (Fig. 4, panel A). A positive trend or correlation was also found when the analysis was done with the type of mutation being Ki67 expression higher in RET positive cases than in RAS positive cases and even lower in RET/RAS negative cases (Fig. 4, panel B). Although not statistically significant, we found that, among all mutations, the p.Met918Thr RET mutation showed the highest proliferation rate (Table 2). The correlation become significant when the analysis was performed between Ki67 positivity and the AF of RET positive cases (Fig. 4, panel C).

Data on the outcome were available in 127/149 cases: 88/127 (69.3\%) patients were free of disease while 39/127 (30.7\%) patients were either dead or with a persistent disease (i.e. biochemical and/or structural disease). In the group of disease free patients, the prevalence of cases smaller than $2 \mathrm{~cm}(n=63)$ was significantly higher than those with larger tumors $(n=25)$. On the contrary in the group of patients dead or with a persistent disease, the prevalence of cases larger than $2 \mathrm{~cm}(n=26)$ was
A

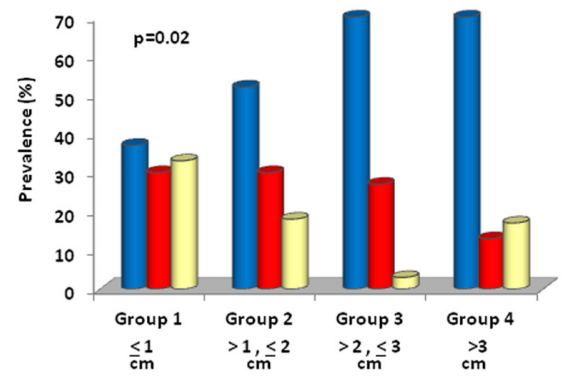

$\mathrm{B} \square{ }_{R E T}$ positive $\square$ RAS positive $\square$ RET/RAS negative

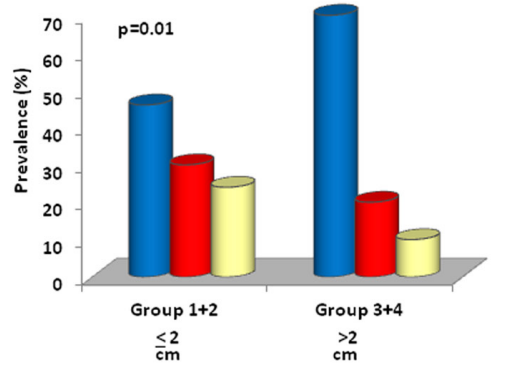

Figure 1

Prevalence of somatic RET and RAS mutations according to tumor size. A statistically significant difference in the mutations profile was observed both when 4 different groups were considered (group 1, $\leq 1 \mathrm{~cm}$; group 2, $>1$ and $\leq 2 \mathrm{~cm}$; group 3, $>2$ and $\leq 3 \mathrm{~cm}$; and group $4,>3 \mathrm{~cm}(P=0.02))$ (panel $A$ ) and when grouped into 2 bigger groups $(1+2, \leq 2 \mathrm{~cm}$ and $3+4,>2 \mathrm{~cm})(P=0.01)$ (panel $\mathrm{B})$. https://ec.bioscientifica.com https://doi.org/10.1530/EC-20-0589 (c) 2021 The authors Published by Bioscientifica Ltd

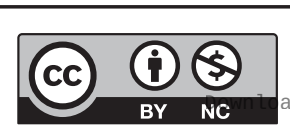

This work is licensed under a Creative Commons Attribution-NonCommercial 4.0 International License. ded from Bioscientifica.com at 04/26/2023 06:11:16AM via free access 
A

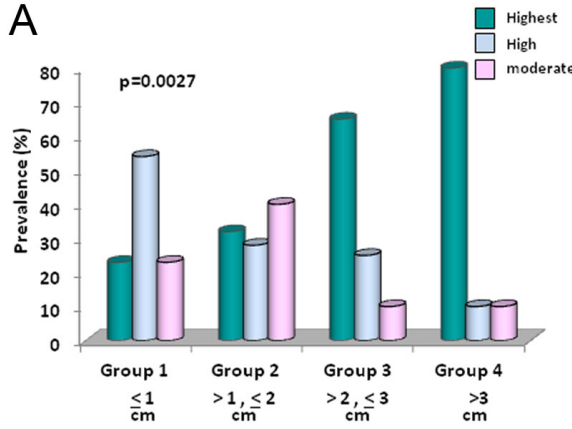

B

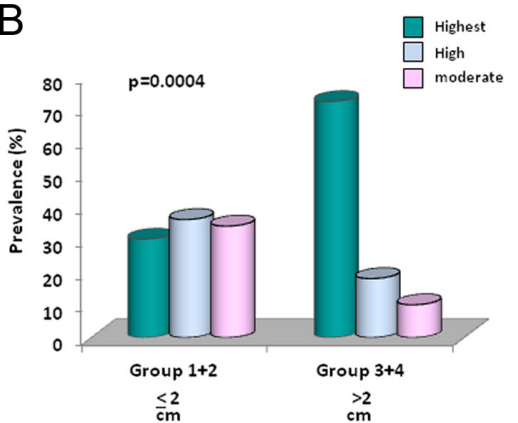

Figure 2

Prevalence of somatic highest, high and moderate RET mutations (17) according to tumor size. Four different groups were considered (group 1 , $\leq 1 \mathrm{~cm}$; group 2,>1 and $\leq 2 \mathrm{~cm}$; group 3,>2 and $\leq 3 \mathrm{~cm}$; and group $4,>3 \mathrm{~cm})$ (panel A); groups A and $B$ vs groups $C$ and $D$ have been considered (panel B). A statistically higher prevalence of the most aggressive RET mutations was observed ( $P=0.0027$ and $P=0.0004$, respectively). significantly higher than those with smaller tumors $(n=13)(P=0.0008)$.

\section{Discussion}

The sporadic form of MTC is mainly characterized by the presence of RET (about $40-50 \%$ of cases) and RAS (about $10-20 \%$ of cases) somatic mutations (Catalogue of Somatic Mutation in Cancer https://cancer.sanger.ac.uk/ cosmic). The p.Met918Thr mutation in exon 16 is the most common RET somatic mutation being present in up to $90 \%$ of $R E T$-positive cases, while $R A S$ gene point mutations in MTC mainly occur in $H$ - and KRAS, and they are usually mutually exclusive with RET mutations. The recent introduction of NGS techniques has largely improved the identification of the molecular alterations involved and causative of many human diseases.
Several studies carried out in MTC confirmed the role of RET and RAS somatic mutations as the main drivers in MTC and only few different genetic alterations have been identified $(2,3,15)$. Nevertheless, a rather large portion of cases are negative for the presence of common somatic gene alterations. In the majority of MTC cases, RET and $R A S$ mutations are mutually exclusive indicating that RETmediated and RAS mediated oncogenic transformations occur separately. Since both RET and RAS alterations lead to an uncontrolled activation of the MAPKinase pathway $(18,19)$ they are considered driver mutations in MTC.

In the present study, we found that the prevalence of RET somatic mutations, any type, was significantly higher in larger than in smaller MTC cases and in particular that the RET ATA highest mutation (i.e. p.Met918Thr) was the most represented in the larger tumors. With these results, we confirmed our previous study (12) that was partially affected by the low sensitivity of the method of
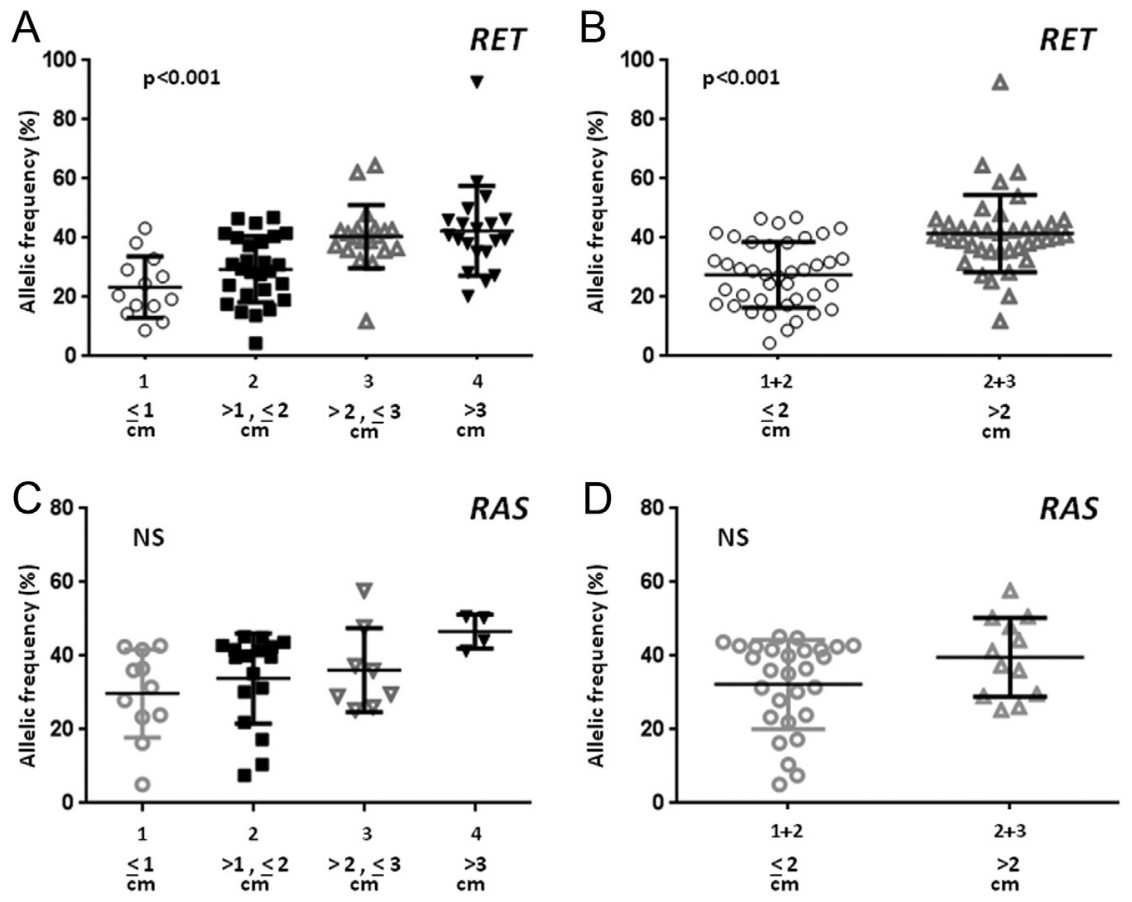

Figure 3

Correlation between the allelic frequency (AF) of the driver mutations and tumor size. RET AF is higher in larger tumors. Four different groups were considered (group 1, $\leq 1 \mathrm{~cm}$; group 2, >1 and $\leq 2 \mathrm{~cm}$; group $3,>2$ and $\leq 3 \mathrm{~cm}$; and group 4 , $>3 \mathrm{~cm})$ (panel A); groups 1 and 2 vs groups 3 and 4 have been considered. $(P<0.001)$ (panel B). RAS AF was not correlated to tumor size when both the four groups (panel $C$ ) and when considered groups 1 and 2 vs groups 3 and 4 (panel D) were considered. 

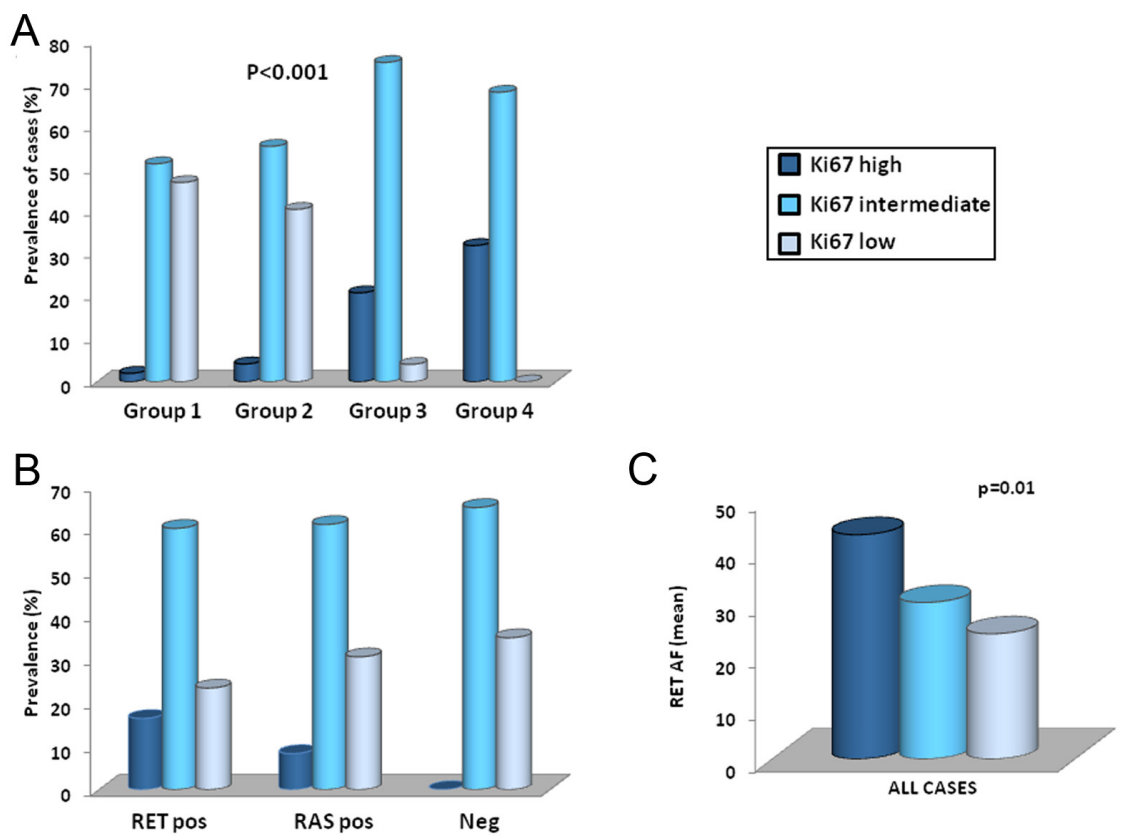

\begin{abstract}
Figure 4
A statistically significant correlation was found when Ki67 low, intermediate and high positivity was correlated to the tumor size (panel A); although not statistically significant, a trend of correlation was observed when Ki67 positivity was analyzed according to the type of mutation (panel B). The correlation of Ki67 positivity was statistically significant when the analysis was performed with the AF of RET mutation in RET positive cases (panel C).
\end{abstract}

sequencing used with the risk to have lost some positive cases especially in the smallest tumors. The prevalence of RET mutations found with NGS can be considered reliable and we can now confirm that the different prevalence of RET in smaller and bigger tumors is true. At variance, a higher proportion of tumors positive for RAS somatic mutation or negative for any mutation was observed in smaller tumors. According to these results, we can hypothesize that three types of MTC tumors exist: those with RAS or noRAS/noRET mutations. At the time of their development they are similar in prevalence but then $R A S$ or noRAS/noRET cases remain smaller likely because of growing slowly. While those with RET, especially p.Met918Thr, mutation becomes bigger likely because of rapidly growing.

A second important observation of the present work is that larger tumors are characterized by a higher AF of RET mutations, and in particular of the p.Met918Thr, with a mean AF of 41.54 vs 26.93 in the smaller. This finding indicates that a bigger number of tumoral cells, almost the totality, are mutated in the bigger tumors but not in

Table 2 Ki67 expression level in RET positive cases.

\begin{tabular}{|c|c|c|c|c|}
\hline \multirow[b]{2}{*}{ Mutation } & \multirow{2}{*}{$\begin{array}{c}\text { Number of } \\
\text { patients }\end{array}$} & \multicolumn{3}{|c|}{ Ki67 } \\
\hline & & Low, $n(\%)$ & Intermediate, $n(\%)$ & High, $n(\%)$ \\
\hline Highest $^{a}$ & 38 & $5(14.8)$ & 23 (29.5) & $10(66.6)$ \\
\hline High & 26 & $8(23.5)$ & $16(20.5)$ & $2(13.4)$ \\
\hline Moderate & 7 & $3(8.8)$ & $4(5.2)$ & 0 \\
\hline Total & 71 & 16 & 43 & 12 \\
\hline
\end{tabular}

a36 M918T and 2 A883F; by chi square: $P=0.089$. the smaller tumors. This was not observed for the AF of RAS mutations that were present in about $30 \%$ of tumoral cells without differences related to the tumor size. These findings support the previous observations that a genetic intra- and inter-tumor heterogeneity and non-clonal origin of some MTC cases exists $(13,14)$. Considering that RET p.Met918Thr mutation has been demonstrated to have the highest transforming ability (20), we can postulate that cells carrying this mutation can duplicate more rapidly and take a growth advantage respect to the non-mutated concomitant cells. The fact that bigger tumors have the RET p.Met918Thr mutation more frequently at a higher AF is in line with this hypothesis.

The higher prevalence of RET somatic mutations, and in particular of the p.Met918Thr, in larger tumors is in keeping with the evidence that larger tumors have a worse outcome $(21,22)$ as shown also in the present series. On this regard, it is useful to recall that RET p.Met918Thr is also the germline mutation of the MEN 2B, whose MTC is the most aggressive and rapidly growing tumor among all genotype of MEN 2 (23). These findings are in keeping with the hypothesis that RET mutations, particularly p.Met918Thr, identify a subgroup of tumors rapidly growing for the presence of a highly transforming mutation and with a more aggressive behavior with respect to those with $R A S$ mutations or without any mutations. The great correlation of Ki67 positivity, that is a well-recognized index of tumor proliferation, with the greater size of the tumor and with a higher percentage of AF of RET in RET positive cases can be considered the

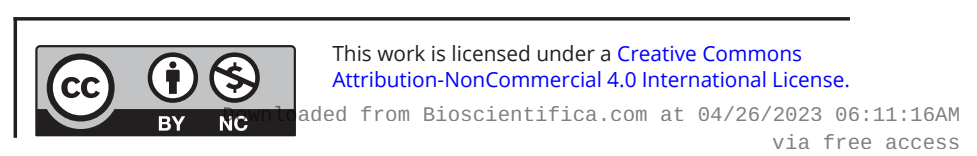


proof of the fact that RET positive cells take a growth advantage with respect to the negative cells (i.e. higher percentage of $\mathrm{AF}$ of the mutation), divide and reproduce more rapidly (i.e. higher Ki67 positivity) thus determining a rapid increase of the tumor respect to RET negative, either RAS positive or negative, cases.

Simultaneously, we can consider that, at least cases with $R A S$ mutations, are more clonal and less aggressive similarly to RAS positive follicular adenomas and carcinomas (24). This behavior has been also reported in colon cancer $(25,26)$ in which both KRAS and NRAS mutations are usually present in the majority of neoplastic cells and have been considered a clonal event in the tumoral transformation. It has been proposed (27, 28 ) that, at variance with PIK3CA and NOTCH1 mutations that instead seem to have a biological behavior similar to that of RET mutations $(13,14), R A S$ mutations would likely accumulate at the beginning of tumor formation thus representing the main driver alteration.

In conclusion, this study highlights the predominant role of RET somatic mutations in MTC tumorigenesis and demonstrates a high prevalence of these alterations in all size categories. We demonstrate that RET mutation prevalence and RET mutation $\mathrm{AF}$ are significantly higher in larger than in smaller tumors indicating that RET alterations are clonal event in cases larger than $2 \mathrm{~cm}$ and subclonal event in small MTC cases. At variance, both the prevalence and the AF of RAS mutations are similar in MTC size categories. Finally, bigger tumors, that have higher prevalence of RET mutations as well as higher level of Ki67 positivity, showed a more aggressive behavior and a worse outcome.

\section{Declaration of interest}

The authors declare that there is no conflict of interest that could be perceived as prejudicing the impartiality of the research reported.

\section{Funding}

This study has been supported by grants to R E from Associazione Italiana per la Ricerca sul Cancro (AIRC, Investigator grant 2018, project code 21790), Agenzia Italiana del Farmaco (AIFA, project code AIFA-2016-02365049), and Progetto di Ricerca di Ateneo (PRA_2018_27) from University of Pisa.

\section{Author contribution statement}

C R designed the study, performed the in silico analysis and prepared the manuscript. T R and C M performed all DNA preparation and the MLPA experiments. A P, V C and $L L$ contributed to patients selection and collection of clinical data. L T and F B reviewed histological slides and gave the final diagnosis of MTC. R C performed all NGS experiments. R E is the team leader, she contributed to the preparation of the manuscript.

\section{References}

1 Romei C, Ciampi R \& Elisei R. A comprehensive overview of the role of the RET proto-oncogene in thyroid carcinoma. Nature Reviews: Endocrinology 201612 192-202. (https://doi.org/10.1038/ nrendo.2016.11)

2 Simbolo M, Mian C, Barollo S, Fassan M, Mafficini A, Neves D, Scardoni M, Pennelli G, Rugge M, Pelizzo MR, et al. High-throughput mutation profiling improves diagnostic stratification of sporadic medullary thyroid carcinomas. Virchows Archiv 2014465 73-78. (https://doi.org/10.1007/s00428-014-1589-3)

3 Agrawal N, Jiao Y, Sausen M, Leary R, Bettegowda C, Roberts NJ, Bhan S, Ho AS, Khan Z, Bishop J, et al. Exomic sequencing of medullary thyroid cancer reveals dominant and mutually exclusive oncogenic mutations in RET and RAS. Journal of Clinical Endocrinology and Metabolism 201398 E364-E369. (https://doi.org/10.1210/ jc. 2012-2703)

4 Wei S, LiVolsi VA, Montone KT, Morrissette JJD \& Baloch ZW. Detection of molecular alterations in medullary thyroid carcinoma using next-generation sequencing: an institutional experience. Endocrine Pathology 201627 359-362. (https://doi.org/10.1007/ s12022-016-9446-3)

5 Ji JH, Oh YL, Hong M, Yun JW, Lee HW, Kim D, Ji Y, Kim DH, Park WY, Shin HT, et al. Identification of driving ALK fusion genes and genomic landscape of medullary thyroid cancer. PLoS Genetics 201511 e1005467. (https://doi.org/10.1371/journal.pgen.1005467)

6 Heilmann AM, Subbiah V, Wang K, Sun JX, Elvin JA,

Chmielecki J, Sherman SI, Murthy R, Busaidy NL, Subbiah I, et al. Comprehensive genomic profiling of clinically advanced medullary thyroid carcinoma. Oncology 201690 339-346. (https://doi. org/10.1159/000445978)

7 Ciampi R, Mian C, Fugazzola L, Cosci B, Romei C, Barollo S, Cirello V, Bottici V, Marconcini G, Rosa PM, et al. Evidence of a low prevalence of ras mutations in a large medullary thyroid cancer series. Thyroid 201323 50-57. (https://doi.org/10.1089/ thy.2012.0207)

8 Fussey JM, Vaidya B, Kim D, Clark J, Ellard S \& Smith JA. The role of molecular genetics in the clinical management of sporadic medullary thyroid carcinoma: a systematic review. Clinical Endocrinology 201991 697-707. (https://doi.org/10.1111/ cen.14060)

9 Vuong HG, Odate T, Ngo HTT, Pham TQ, Tran TTK, Mochizuki K, Nakazawa T, Katoh R \& Kondo T. Clinical significance of RET and RAS mutations in sporadic medullary thyroid carcinoma: a metaanalysis. Endocrine-Related Cancer 201825 633-641. (https://doi. org/10.1530/ERC-18-0056)

10 Mian C, Pennelli G, Barollo S, Cavedon E, Nacamulli D, Vianello F, Negro I, Pozza G, Boschin IM, Pelizzo MR, et al. Combined RET and Ki-67 assessment in sporadic medullary thyroid carcinoma: a useful tool for patient risk stratification. European Journal of Endocrinology 2011 164 971-976. (https://doi.org/10.1530/EJE-11-0079)

11 Elisei R, Cosci B, Romei C, Bottici V, Renzini G, Molinaro E, Agate L, Vivaldi A, Faviana P, Basolo F, et al. Prognostic significance of somatic RET oncogene mutations in sporadic medullary thyroid cancer: a 10-year follow-up study. Journal of Clinical Endocrinology and Metabolism 200893 682-687. (https://doi.org/10.1210/jc.2007-1714)

12 Romei C, Ugolini C, Cosci B, Torregrossa L, Vivaldi A, Ciampi R, Tacito A, Basolo F, Materazzi G, Miccoli P, et al. Low prevalence of the somatic M918T RET mutation in micro-medullary thyroid cancer. Thyroid 201222 476-481. (https://doi.org/10.1089/thy.2011.0358)

13 Romei C, Ciampi R, Casella F, Tacito A, Torregrossa L, Ugolini C, Basolo F, Materazzi G, Vitti P \& Elisei R. RET mutation heterogeneity in primary advanced medullary thyroid cancers and their metastases. Oncotarget 20189 9875-9884. (https://doi.org/10.18632/ oncotarget.23986) https://ec.bioscientifica.com https://doi.org/10.1530/EC-20-0589 (c) 2021 The authors Published by Bioscientifica Ltd

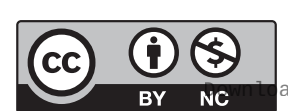

This work is licensed under a Creative Commons Attribution-NonCommercial 4.0 International License. ded from Bioscientifica.com at 04/26/2023 06:11:16AM 
14 Eng C, Mulligan LM, Healey CS, Houghton C, Frilling A, Raue F, Thomas GA \& Ponder BA. Heterogeneous mutation of the RET protooncogene in subpopulations of medullary thyroid carcinoma. Cancer Research 199656 2167-2170.

15 Ciampi R, Romei C, Ramone T, Prete A, Tacito A, Cappagli V, Bottici V, Viola D, Torregrossa L, Ugolini C, et al. Genetic landscape of somatic mutations in a large cohort of sporadic medullary thyroid carcinomas studied by next-generation targeted sequencing. iScience 201920 324-336. (https://doi.org/10.1016/j.isci.2019.09.030)

16 Fuchs TL, Nassour AJ, Glover A, Sywak MS, Sidhu SB, Delbridge LW, Clifton-Bligh RJ, Gild ML, Tsang V, Robinson BG, et al. A proposed grading scheme for medullary thyroid carcinoma based on proliferative activity (Ki-67 and mitotic count) and coagulative necrosis. American Journal of Surgical Pathology 202044 1419-1428. (https://doi.org/10.1097/PAS.0000000000001505)

17 Wells SA Jr, Asa SL, Dralle H, Elisei R, Evans DB, Gagel RF, Lee N, Machens A, Moley JF, Pacini F, et al. Revised American Thyroid Association guidelines for the management of medullary thyroid carcinoma. Thyroid 201525 567-610. (https://doi.org/10.1089/ thy.2014.0335)

18 Mulligan LM. GDNF and the RET receptor in cancer: new insights and therapeutic potential. Frontiers in Physiology 201891873. (https://doi.org/10.3389/fphys.2018.01873)

19 Stalnecker CA \& Der CJ. RAS, wanted dead or alive: Advances in targeting RAS mutant cancers. Science Signaling 202013 eaay6013. (https://doi.org/10.1126/scisignal.aay6013)

20 Cosci B, Vivaldi A, Romei C, Gemignani F, Landi S, Ciampi R, Tacito A, Molinaro E, Agate L, Bottici V, et al. In silico and in vitro analysis of rare germline allelic variants of RET oncogene associated with medullary thyroid cancer. Endocrine-Related Cancer 201118 603-612. (https://doi.org/10.1530/ERC-11-0117)

21 Gharib H, McConahey WM, Tiegs RD, Bergstralh EJ, Goellner JR, Grant CS, van Heerden JA, Sizemore GW \& Hay ID. Medullary thyroid carcinoma: clinicopathologic features and long-term follow-up of 65 patients treated during 1946 through 1970.
Mayo Clinic Proceedings 199267 934-940. (https://doi.org/10.1016/ s0025-6196(12)60923-9)

22 Machens A \& Dralle H. Biological relevance of medullary thyroid microcarcinoma. Journal of Clinical Endocrinology and Metabolism 2012 97 1547-1553. (https://doi.org/10.1210/jc.2011-2534)

23 Elisei R, Matrone A, Valerio L, Molinaro E, Agate L, Bottici V, Viola D, Giani C, Cappagli V, Latrofa F, et al. Fifty years after the first description, MEN 2B syndrome diagnosis is still late: descriptions of two recent cases. Journal of Clinical Endocrinology and Metabolism 2019 104 2520-2526. (https://doi.org/10.1210/jc.2018-02102)

24 Paniza ACJ, Mendes TB, Viana MDB, Thomaz DMD, Chiappini PBO, Colozza-Gama GA, Lindsey SC, de Carvalho MB, Alves VAF, Curioni $\mathrm{O}$, et al. Revised criteria for diagnosis of NIFTP reveals a better correlation with tumor biological behavior. Endocrine Connections 20198 1529-1538. (https://doi.org/10.1530/EC-19-0459)

25 Normanno N, Rachiglio AM, Lambiase M, Martinelli E, Fenizia F, Esposito C, Roma C, Troiani T, Rizzi D, Tatangelo F, et al. Heterogeneity of KRAS, NRAS, BRAF and PIK3CA mutations in metastatic colorectal cancer and potential effects on therapy in the Capri GOIM trial. Annals of Oncology 201526 1710-1714. (https:// doi.org/10.1093/annonc/mdv176)

26 Dienstmann R, Elez E, Argiles G, Matos I, Sanz-Garcia E, Ortiz C, Macarulla T, Capdevila J, Alsina M, Sauri T, et al. Analysis of mutant allele fractions in driver genes in colorectal cancer - biological and clinical insights. Molecular Oncology 201711 1263-1272. (https://doi. org/10.1002/1878-0261.12099)

27 Joung JG, Oh BY, Hong HK, Al-Khalidi H, Al-Alem F, Lee HO, Bae JS, Kim J, Cha HU, Alotaibi M, et al. Tumor heterogeneity predicts metastatic potential in colorectal cancer. Clinical Cancer Research 201723 7209-7216. (https://doi.org/10.1158/1078-0432.CCR-170306)

28 Sottoriva A, Kang H, Ma Z, Graham TA, Salomon MP, Zhao J, Marjoram P, Siegmund K, Press MF, Shibata D, et al. A big bang model of human colorectal tumor growth. Nature Genetics 201547 209-216. (https://doi.org/10.1038/ng.3214)

Received in final form 01 December 2020

Accepted 15 January 2021

Accepted Manuscript published online 22 January 2021
This work is licensed under a Creative Commons Attribution-NonCommercial 4.0 International License. ded from Bioscientifica.com at 04/26/2023 06:11:16AM 